\begin{tabular}{|c|c|}
\hline Title & $\begin{array}{l}\text { Role of vertical eddy heat flux in the response of tropical tropopause temperature to changes in tropical sea surface } \\
\text { temperature }\end{array}$ \\
\hline Author(s) & Y oshida, Kohei; Y amazaki, Koji \\
\hline Citation & $\begin{array}{l}\text { Journal of Geophysical Research, A tmospheres, 115, D01108 } \\
\text { https://doi.org/10.1029/2009JD012783 }\end{array}$ \\
\hline Issue Date & 2010-01-13 \\
\hline Doc URL & http:/hdl.handle.net/2115/49419 \\
\hline Rights & Copyright 2010 by the A merican Geophysical Union \\
\hline Type & article \\
\hline File Information & JGRA 115_D01108.pdf \\
\hline
\end{tabular}

Instructions for use 


\title{
Role of vertical eddy heat flux in the response of tropical tropopause temperature to changes in tropical sea surface temperature
}

\author{
Kohei Yoshida $^{1}$ and Koji Yamazaki ${ }^{2}$ \\ Received 3 July 2009; revised 2 September 2009; accepted 15 September 2009; published 13 January 2010.
}

[1] We performed numerical experiments using an atmospheric general circulation model to assess the effect of convections associated with various tropical sea surface temperature (SST) fields on the tropical tropopause (TT). Three experiments were designed with different patterns of tropical SST: increasing and decreasing mean tropical SST, enhanced and weakened longitudinal gradient of tropical SST, and observed SST corresponding to strong El Niño-Southern Oscillation (ENSO) events. The results reveal that vertical advection plays an important role in controlling seasonal variation in TT temperature. In the case of a large (small) longitudinal gradient of tropical SST, the vertical eddy heat flux $\left(\overline{w^{\prime} \theta^{\prime}}\right)$ diverges strongly (weakly) around the TT, resulting in cooling (warming) of the TT. Divergence of the vertical eddy heat flux is a primary controlling factor of variations in interannual TT temperature, especially during the peak of El Niño events. Analysis of ERA-Interim and ERA-40 data supports our results regarding the influence of vertical eddy heat flux on TT temperature. Divergence of vertical eddy heat flux at the TT layer is sensitive to the "strength" of the Matsuno-Gill-type tropical stationary wave response; this divergence appears to explain variations in the observed TT temperature associated with ENSO.

Citation: Yoshida, K., and K. Yamazaki (2010), Role of vertical eddy heat flux in the response of tropical tropopause temperature to changes in tropical sea surface temperature, J. Geophys. Res., 115, D01108, doi:10.1029/2009JD012783.

\section{Introduction}

[2] The tropical tropopause (TT) region plays an important role in governing the large-scale distribution of moisture in the stratosphere because air entering the stratosphere is strongly dehydrated in the TT region [Holton and Gettleman, 2001; Hatsushika and Yamazaki, 2003; Fueglistaler et al., 2005]. Hence, the structure of the TT and its spatial and temporal variations have been investigated in several previous studies [e.g., Highwood and Hoskins, 1998; Hartmann, 2007].

[3] The TT temperature varies seasonally, being lower in the boreal winter and higher in the boreal summer. Two mechanisms have been invoked to explain this seasonal variation. First, stratospheric circulation (characterized by upward flow in the tropics and poleward-downward flow in the extratropics, known as Brewer-Dobson (B-D) circulation) controls the TT temperature by diabatic upwelling [Yulaeva et al., 1994; Holton et al., 1995]. The wave forcing caused by planetary-scale, synoptic-scale, and gravity wave dissipations in the subtropical and extratropical stratosphere, mainly in the winter hemisphere, drags on stratospheric poleward flow and induces upward motion in the tropics

\footnotetext{
${ }^{1}$ Graduate School of Environmental Science, Hokkaido University, Sapporo, Japan.

${ }^{2}$ Faculty of Environmental Earth Science, Hokkaido University, Sapporo, Japan.

Copyright 2010 by the American Geophysical Union. 0148-0227/10/2009JD012783\$09.00
}

(the so-called "stratospheric pump") [Haynes et al., 1991; Plumb and Eluszkiewicz, 1999]. This forcing is stronger in the Northern Hemisphere and induces stronger upward motion and lower temperatures during the boreal winter.

[4] The second mechanism that influences the seasonality of TT temperature is the effect of localized meridional circulation in the TT region caused by equatorial waves [Kerr-Munslow and Norton, 2006]. Such waves are excited mainly by longitudinally localized deep convection around the equatorial western Pacific. Because the localized deep convection occurs around the equator during the boreal winter and around $15^{\circ} \mathrm{N}$ during the boreal summer, this wave forcing is stronger near the TT during the boreal winter. Therefore, upward motion is stronger and temperatures are lower during the boreal winter. In addition, on the basis of the results of an idealized atmospheric general circulation model (AGCM) experiment, Norton [2006] suggested that when the localized deep convection is shifted far from the equator (conditions corresponding to the boreal summer), tropical wave activity is weakened in the TT region.

[5] Seasonal variations in convection in the tropics are caused by changes in sea surface temperature (SST) distribution. The annual time scale is the dominant period driving such variations, but other time scales also make a contribution. For example, the El Niño-Southern Oscillation (ENSO) is known to strongly influence tropical temperature structure and wave activity [Trenberth and Smith, 2006], and the SST distribution in the Pacific is close to being zonally uniform in El Niño years because of weakening of the 
longitudinal SST gradient in the tropical Pacific. Consequently, it is important to investigate how the TT temperature varies at time scales other than annual and in realistic situations.

[6] Norton [2006] performed simulations using a seasonally fixed model with idealized diabatic heating in the tropical troposphere following the simple model employed by Gill [1980]. In this approach, the heating distribution was prescribed as Gaussian in the horizontal and vertical. In reality, however, diabatic heating in the tropical troposphere is caused mainly by moist convection and depends on tropical SST.

[7] In the present study, we examine the response of the zonal mean TT temperature to various tropical SST fields via three experiments performed using an AGCM. In the first experiment, we varied the longitudinal gradient of tropical SST. The second experiment was performed with variable mean tropical SST. These two experiments were designed to investigate how TT temperature changes with changing zonal mean part of an ENSO-like SST field and with perturbation of this field. Finally, the third experiment was performed with realistic SST during the 1997-1998 El Niño period.

[8] Following the methodology of Kerr-Munslow and Norton [2006], we performed a thermodynamic budget analysis within the transformed Eulerian mean framework. We found that the vertical eddy heat flux, which has not been considered in previous studies, strongly influences the TT temperature.

[9] The remainder of this paper is organized as follows. Section 2 describes the data set, model, and experiments. Section 3 deals with changes in precipitation, and section 4 discusses changes in temperature and meridional circulation near the TT. Section 5 describes wave activity that drives meridional circulation, and in section 6 we assess the thermodynamic budget in the tropics. Section 7 considers the mechanism of vertical eddy heat flux, and section 8 compares the results of realistic SST experiments with observations. Finally, section 9 provides a discussion and summary of the conclusions.

\section{Data, Model, and Experiments}

[10] The AGCM used in this study was developed by the Center for Climate System Research and the National Institute for Environmental Studies [Numaguti et al., 1995]. The resolution is T42L24, with the model top at $0.4 \mathrm{hPa}$. The model has state-of-the-art physical processes and was used previously to study the TT layer [Hatsushika and Yamazaki, 2003]. We define the TT as the coldest region (the so-called cold point tropopause) between $10^{\circ} \mathrm{N}$ and $10^{\circ} \mathrm{S}$. The TT in this model is located at about $90 \mathrm{hPa}$ and is fixed at $90 \mathrm{hPa}$ hereafter.

[11] Three experiments were performed with various SST fields. Each experiment was designed to assess the response of TT temperature when the tropics are forced by different SST fields between $15^{\circ} \mathrm{S}$ and $15^{\circ} \mathrm{N}$. The SST distributions used in the experiments were as follows: (1) standard SST (control run or CTR), (2) changing longitudinal gradient of tropical SST (experiment 1 or EXP1), (3) changing mean tropical SST (EXP2), and (4) observed SST (EXP3).
[12] The standard SST case uses the seasonally varying climatological SST field provided by the Atmospheric Model Intercomparison Project (AMIP I) [Gates, 1992]. The SST fields used in EXP1 and EXP2 are based on the AMIP SST and are given simple spatial change in the tropics.

[13] The SST is decomposed into a zonal mean part and a perturbation part, as follows:

$$
\mathrm{SST}=\overline{\mathrm{SST}}+\mathrm{SST}^{\prime}
$$

where $\overline{\mathrm{SST}}$ is the zonal mean SST and $\mathrm{SST}^{\prime}$ is the departure from the zonal mean. In EXP1, the perturbation part of AMIP SST is doubled or halved as follows:

$$
\begin{aligned}
{\left[2 \mathrm{SST}^{\prime}\right] } & =\overline{\mathrm{SST}}+2 \mathrm{SST}^{\prime} \\
{\left[0.5 \mathrm{SST}^{\prime}\right] } & =\overline{\mathrm{SST}}+0.5 \mathrm{SST}^{\prime} .
\end{aligned}
$$

[14] In EXP2, the zonal mean part of AMIP SST increases or decreases by $1 \mathrm{~K}$, as follows:

$$
\begin{aligned}
& {[\overline{\mathrm{SST}}+1]=\overline{\mathrm{SST}}+1[\mathrm{~K}]+\mathrm{SST}^{\prime}} \\
& {[\overline{\mathrm{SST}}-1]=\overline{\mathrm{SST}}-1[\mathrm{~K}]+\mathrm{SST}^{\prime}}
\end{aligned}
$$

[15] Figure 1 shows the annual mean SST field for each experiment (except EXP3). Figure 1a shows the annual mean SST used in the standard SST field, and Figure 1b shows the SST field in the case of the perturbation part being doubled $\left(2 \mathrm{SST}^{\prime}\right)$. There exists a large longitudinal SST difference between the eastern and western tropical Pacific. Figure 1c shows the SST field in the case of the perturbation part being halved $\left(0.5 \mathrm{SST}^{\prime}\right)$. There exists a small temperature difference between the eastern and western tropical Pacific. Figures 1d and 1e show the cases in which the tropical SST fields are increased $(\overline{\mathrm{SST}}+1)$ and decreased $(\overline{\mathrm{SST}}-1)$ by $1 \mathrm{~K}$, respectively.

[16] In CTR, EXP1, and EXP2, the model was integrated for 20 years, with the model output for the last 15 years being analyzed; subsequently, the monthly annual cycle of climatology was calculated.

[17] EXP3 was performed using observed SST for the period between January 1996 and December 1999 as a fourmember initial value ensemble. Data sets in 1 January of 4 years in CTR were applied as initial values for each member. Integration using the observed SST started in January 1996. Ensemble mean was calculated after analysis was made for each member. During this period, a distinct El Niño event took place, peaking in January 1998. The observed SST field was provided by the Hadley Centre Global Sea Ice and Sea Surface Temperature data on a $1^{\circ} \times 1^{\circ}$ grid (HadISST1.1). These SST data sets were interpolated to match the T42 resolution.

[18] To confirm the validity of the model results, the results of EXP3 were compared with those of ERA-Interim, which is the latest reanalysis data set provided by the European Centre for Medium-Range Weather Forecasts (ECMWF) [Simmons et al., 2006; Uppala et al., 2008]. The ERA-Interim data set has a smaller assimilation increment of temperature around the TT than the ECMWF 40 Year Re-Analysis (ERA-40) [Fueglistaler et al., 2009], which is a 


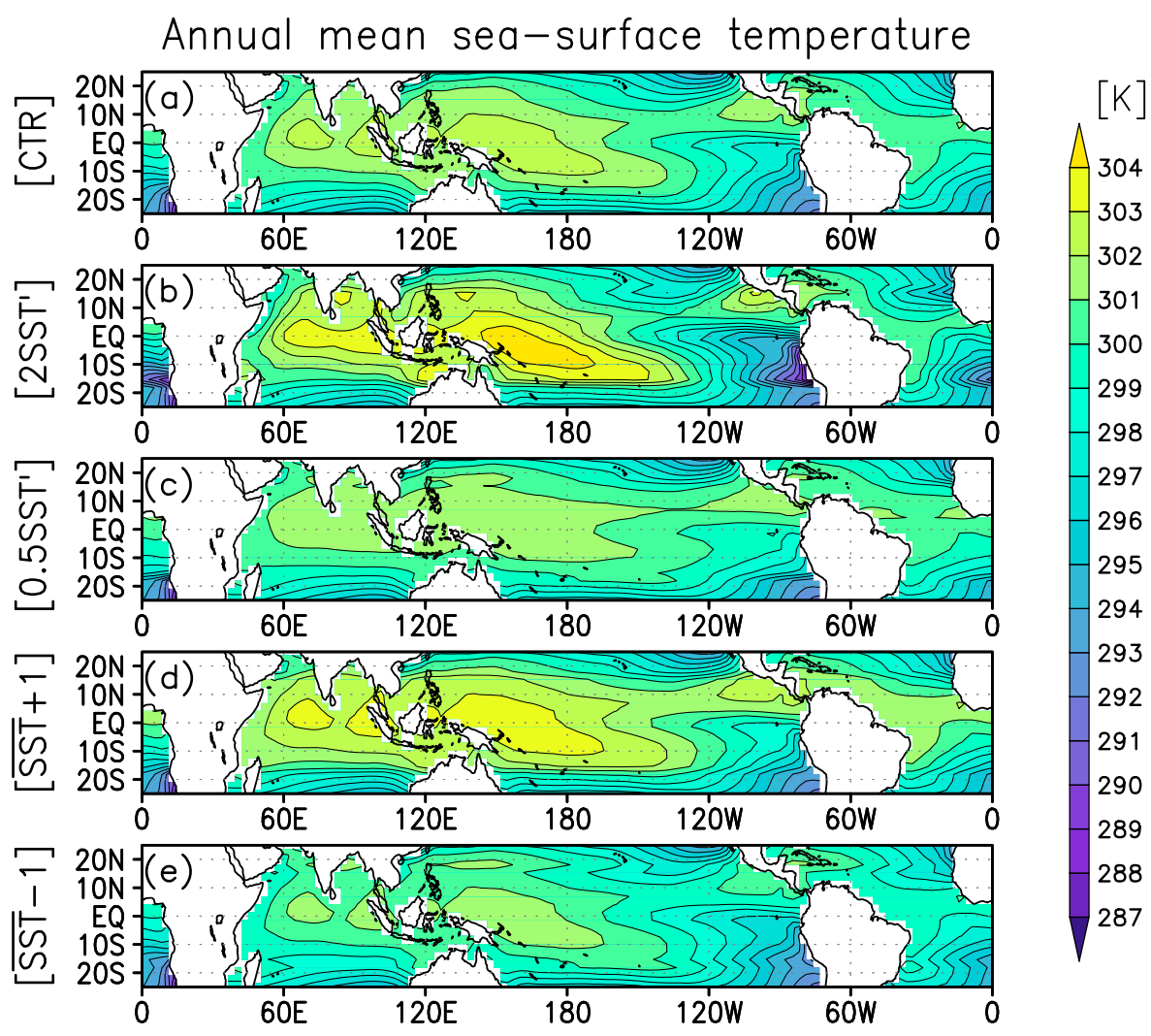

Figure 1. Annual mean sea surface temperature (K) fields used for AGCM experiments. (a) CTR, (b) $2 \mathrm{SST}^{\prime}$, (c) $0.5 \mathrm{SST}^{\prime}$, (d) $\overline{\mathrm{SST}}+1$, and (e) $\overline{\mathrm{SST}}-1$.

former reanalysis data set [see Simmons and Gibson, 2000; Uppala et al., 2005]; therefore, ERA-Interim is an appropriate data set for this study. The data period used in this study is from January 1989 to December 2008. The ERA-40 data set is also compared. Kerr-Munslow and Norton [2006] used ECMWF 15 Year Re-Analysis (ERA-15), which has weaker vertical velocity in the TT region than ERA-Interim and ERA-40.

\section{Precipitation}

[19] To assess how convection is modified by SST change, Figure 2 shows precipitation in CTR and the difference from CTR for each of the other runs. Figure 2 shows annual mean precipitation and its anomalies from CTR and their zonal mean values.

[20] Figure 2a (left) shows that the region in CTR with high precipitation corresponds to the Intertropical Convergence Zone and the South Pacific Convergence Zone. The region of maximum precipitation is located around the tropical western Pacific. Figure 2a (right) shows that the zonal mean precipitation has a sharp peak at around $7^{\circ} \mathrm{N}$.

[21] Figure 2b (left) shows that precipitation increases around the International Date Line in areas south of the equator and decreases along $10^{\circ} \mathrm{N}$, except around $160^{\circ} \mathrm{E}$ in $2 \mathrm{SST}^{\prime}$. Thus, the longitudinal gradient of precipitation increases in the tropics. Figure $2 \mathrm{~b}$ (right) shows that the shape of the major precipitation band becomes smooth in the tropics because zonal mean precipitation increases along $10^{\circ} \mathrm{S}$ and decreases along $7^{\circ} \mathrm{N}$ in $2 \mathrm{SST}^{\prime}$. In addition, the total precipitation in $2 \mathrm{SST}^{\prime}$ is similar to that in CTR in the tropics.

[22] Figure 2c (left) shows that the precipitation anomaly pattern in $0.5 \mathrm{SST}^{\prime}$ is almost the opposite of that in $2 \mathrm{SST}^{\prime}$ (Figure 2b, left). Thus, the longitudinal gradient of precipitation is reduced, and Figure $2 \mathrm{c}$ (right) shows that the zonal mean precipitation maximum at $7^{\circ} \mathrm{N}$ is more pronounced than that of CTR.

[23] Figure 2d (left) shows a precipitation increase along $10^{\circ} \mathrm{N}$ and $10^{\circ} \mathrm{S}$ in $\overline{\mathrm{SST}}+1$, whereas it is suppressed along $20^{\circ} \mathrm{N}$ and $20^{\circ} \mathrm{S}$. Figure $2 \mathrm{~d}$ (right) shows that the zonal mean precipitation increases in the tropics, especially at $12^{\circ} \mathrm{S}$ and $12^{\circ} \mathrm{N}$, whereas it decreases at around $20^{\circ} \mathrm{S}$ and $20^{\circ} \mathrm{N}$. Figure 2e shows that the precipitation anomaly pattern in $\overline{\mathrm{SST}}-1$ is almost the opposite of that in $\overline{\mathrm{SST}}+1$ (Figure $2 \mathrm{~d}$ ).

\section{Temperature and Meridional Circulation}

[24] Figure 3 shows meridional structures of the annual mean zonal mean temperature anomalies and residual mean stream function anomalies. Figure 3a shows that in $2 \mathrm{SST}^{\prime}$, the temperature increases in the tropical troposphere and decreases in the tropical lower stratosphere and TT. In addition, the residual mean vertical velocity increases between $15^{\circ} \mathrm{S}$ and $5^{\circ} \mathrm{N}$ and decreases at around $10^{\circ} \mathrm{N}$ in the upper troposphere. These changes in the upper tropical troposphere correspond to the positive precipitation anomalies around $10^{\circ} \mathrm{S}$ and negative anomalies around $5^{\circ} \mathrm{N}$ (see dashed line in Figure 2b, right). Anomalies of residual mean stream function between $20^{\circ} \mathrm{N}$ and $20^{\circ} \mathrm{S}$ in the lower 

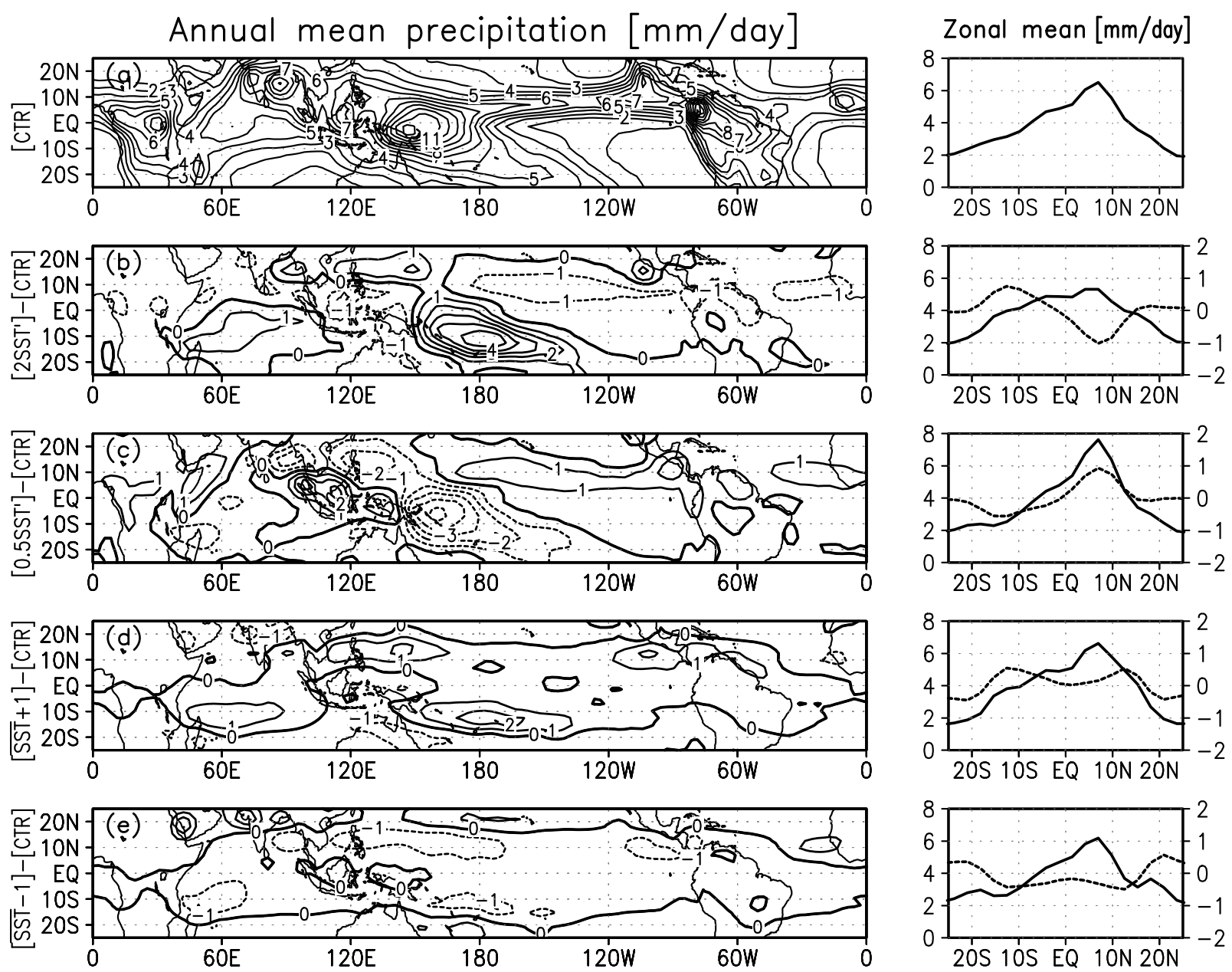

Figure 2. (left) Annual mean precipitation field in (a) CTR and the differences between CTR and (b) $2 \mathrm{SST}^{\prime}$, (c) $0.5 \mathrm{SST}^{\prime}$, (d) $\overline{\mathrm{SST}}+1$, and (e) $\overline{\mathrm{SST}}-1$. (right) Solid lines indicate annual mean zonal mean precipitation in each experiment (left axis), and dashed lines indicate the difference from CTR (right axis).

stratosphere indicate the presence of anomalies of upward flow in the TT and poleward flow in the subtropical lower stratosphere, although the anomaly of the residual mean circulation is weak. The temperature in the equatorial lower stratosphere decreases in association with the ascending anomaly at around $70 \mathrm{hPa}$. The weak anomalous cells do not seem to be able to quantitatively make the temperature decrease in the TT region and the lower tropical stratosphere. This issue will be discussed in section 4 by heat budget analysis. The zero line for the temperature anomaly is located near $100 \mathrm{hPa}$. Temperature shows an increase in the extratropical stratosphere.

[25] In contrast, Figure $3 \mathrm{~b}$ shows that temperature decreases in the tropical troposphere and increases in the tropical lower stratosphere in $0.5 \mathrm{SST}^{\prime}$. The anomaly of the residual mean stream function indicates downwelling around the TT. The zero line for the temperature anomaly is located near $110 \mathrm{hPa}$, slightly lower than the zero line in $2 \mathrm{SST}^{\prime}$ (Figure 3a). Except for the altitude of the zero line of temperature, the result of the $0.5 \mathrm{SST}^{\prime}$ experiment is the opposite of that of the $2 \mathrm{SST}^{\prime}$ experiment.

[26] In EXP1, it is interesting that despite the minor anomaly in total tropical precipitation, the tropical tropo- spheric temperature increases, probably because of a change in the distribution of precipitation. The warming in the troposphere shows a maximum at $150 \mathrm{hPa}$, mainly caused by the vertical eddy heat flux. This effect is discussed in detail in sections 6 and 7 .

[27] Figure $3 \mathrm{c}$ reveals that the temperature shows a marked increase in the tropical troposphere and decreases around the equator at $50 \mathrm{hPa}$. The zero line of the temperature anomaly is located near $80 \mathrm{hPa}$, and most of the extratropical stratosphere is warmed. The upward flow is intensified in the tropics, and a downward flow anomaly is generated in the extratropical stratosphere.

[28] Figure 3d shows patterns in temperature and residual stream function almost opposite to the result obtained for the $\overline{\mathrm{SST}}+1$ experiment (Figure $3 \mathrm{c}$ ), except for the zero line of temperature near $90 \mathrm{hPa}$. B-D circulation is intensified in $\overline{\mathrm{SST}}+1$ and weakened in $\overline{\mathrm{SST}}-1$. Dynamical temperature changes due to vertical flow are pronounced in the stratosphere in EXP2, which shows a strong relationship between temperature anomalies and residual circulation anomalies in the upper TT layer. This relationship is not seen in EXP1 because of the use of a different SST field. Figure 3 shows that the temperature anomalies between 70 and $90 \mathrm{hPa}$ in 

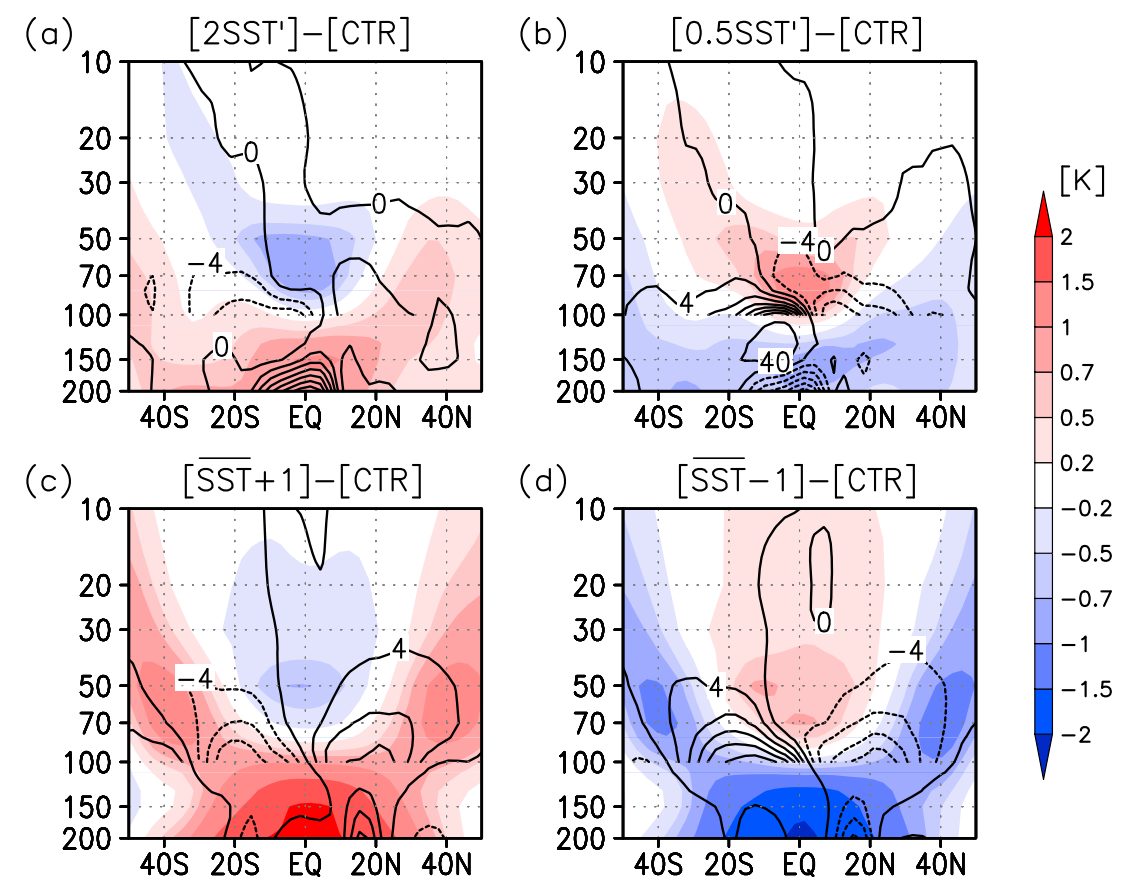

Figure 3. Annual mean cross sections of differences from CTR in zonal mean temperature (K, color bar) and the residual mean stream function $\left(\mathrm{kg} \mathrm{m}^{-1} \mathrm{~s}^{-1}\right.$, contours) for (a) $2 \mathrm{SST}^{\prime}$, (b) $0.5 \mathrm{SST}^{\prime}$, (c) $\overline{\mathrm{SST}}+1$, and (d) $\overline{\mathrm{SST}}-1$. The contour interval is $4 \mathrm{~kg} \mathrm{~m}^{-1} \mathrm{~s}^{-1}$ above $100 \mathrm{hPa}$ and $40 \mathrm{~kg} \mathrm{~m}^{-1} \mathrm{~s}^{-1}$ below $100 \mathrm{hPa}$.

EXP1 have a larger amplitude than those in EXP2, despite the weak circulations around the TT.

[29] The above results provide two questions. First, what is the cause of the residual circulation anomalies in the lower stratosphere and the TT layer? Second, the zonal mean temperature anomaly response of EXP1 between 70 and $90 \mathrm{hPa}$ in the tropics is not in agreement with residual circulation anomalies. Are there any other effects in addition to residual circulation?

[30] To understand how residual circulation is affected by wave forcing near the TT, the Eliassen-Palm (E-P) fluxes of these runs are analyzed, along with the circulations, in section 5. Furthermore, to understand the cause of TT temperature change, the transformed Eulerian mean (TEM) thermodynamics budget is analyzed in section 6 .

\section{E-P Flux and Meridional Circulation}

[31] Figure 4 shows anomalies of E-P flux and residual mean stream function in the upper troposphere and lower stratosphere. These results indicate that wave forcing drives residual mean meridional circulation around the TT.

[32] Figure 4a shows that E-P flux anomalies in $2 \mathrm{SST}^{\prime}$ head from the equatorial upper troposphere to the lower stratosphere and into the subtropical upper troposphere, causing divergence in the equatorial upper troposphere and convergence in the surrounding region. The poleward flow in the tropical stratosphere, driven by this wave forcing, induces upward flow around the TT.

[33] In Figure $4 \mathrm{~b}, 0.5 \mathrm{SST}^{\prime}$ produces the opposite anomaly in E-P flux to that obtained in $2 \mathrm{SST}^{\prime}$, causing convergence in the equatorial upper troposphere and divergence in the surrounding region. The equatorward residual mean meridional circulation anomalies, driven by anomalies of wave forcing opposite to those obtained in $2 \mathrm{SST}^{\prime}$, induce downward residual mean vertical circulation anomalies in the TT region.

[34] Figure 4c shows that E-P flux anomalies in $\overline{\mathrm{SST}}+1$ diverge slightly from the upper equatorial troposphere and converge weakly in the subtropical upper troposphere, corresponding to the residual mean stream function anomalies. The poleward circulation anomalies in the midlatitude stratosphere are driven by convergence of the E-P flux anomaly around the subtropical lower stratosphere. The vertical motion around the TT is enhanced to compensate for poleward circulation, and its amplitude and spatial range are larger than those in $2 \mathrm{SST}^{\prime}$. Figure $4 \mathrm{~d}$ shows that the E-P flux anomaly in $\overline{\mathrm{SST}}-1$ results in almost the opposite residual mean meridional circulation to that obtained in $\overline{\mathrm{SST}}+1$.

[35] There exists a difference between EXP1 and EXP2 regarding whether the greatest change is seen in midlatitude large-scale waves or equatorial waves. In EXP1, the residual mean meridional circulation changes with large-scale equatorial waves excited from the tropical upper troposphere; this change is localized in the TT region and is consistent with the results of Norton [2006]. In EXP2, the residual mean meridional circulation around the TT changes with E-P flux in the subtropical lower stratosphere, which corresponds to changes in B-D circulation. The E-P flux changes in the subtropical lower stratosphere are mostly caused by changes in synoptic waves (zonal wave number 3-6). A large (small) meridional temperature gradient in the troposphere, arising from the enhancement (reduction) of convection, induces a strong (weak) subtropical jet by about $4 \mathrm{~m} \mathrm{~s}^{-1}$ increment at its peak (not shown). Because the wave activity is modified by change of the amplitude of the 


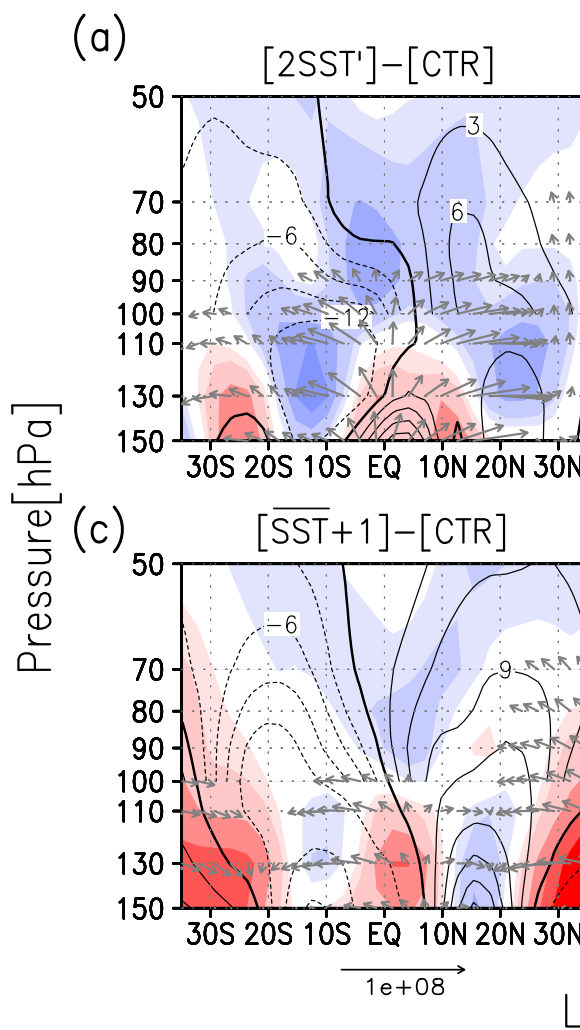

(b)

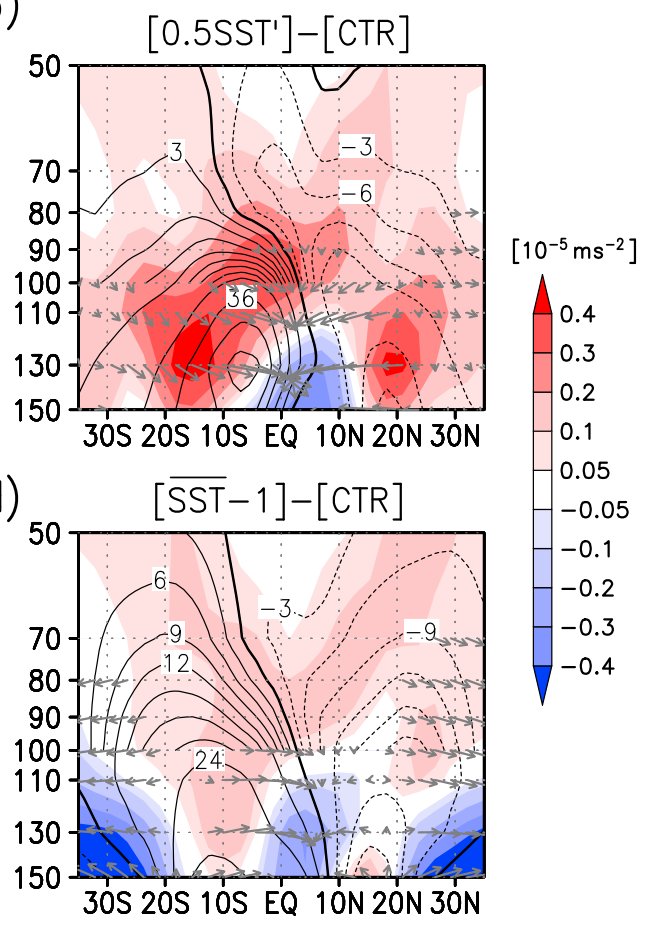

Latitude

Figure 4. Annual mean cross sections of differences from CTR of the residual mean stream function (kg m${ }^{-1} \mathrm{~s}^{-1}$, contours), the E-P flux ( $\mathrm{m}^{2} \mathrm{~s}^{-2}$, arrows), and E-P flux divergence ( $\mathrm{m} \mathrm{s}^{-2}$, color bar) for (a) $2 \mathrm{SST}^{\prime}$, (b) $0.5 \mathrm{SST}^{\prime}$, (c) $\overline{\mathrm{SST}}+1$, and (d) $\overline{\mathrm{SST}}-1$. The contour interval is $3 \mathrm{~kg} \mathrm{~m}^{-1} \mathrm{~s}^{-1}$ above $100 \mathrm{hPa}$ and $12 \mathrm{~kg} \mathrm{~m}^{-1} \mathrm{~s}^{-1}$ below $100 \mathrm{hPa}$. The vertical component of the E-P flux is multiplied by 200 .

westerlies, it is suggested that a change in the subtropical jet affects the intensity of the stratospheric pump. This result is in good agreement with the findings of Olsen et al. [2007], which indicate that variation in the convection modifies large-scale wave propagation in the extratropics and amplitude of the B-D circulation via change in the subtropical jet.

\section{TEM Thermodynamic Analyses}

[36] Here we assess the thermodynamic budget in the TT layer using the TEM thermodynamics equation in $\log p$ coordinates [see Andrews et al., 1987]:

$$
\begin{aligned}
\frac{\partial \bar{\theta}}{\partial t}= & -\frac{\bar{v}^{*}}{a} \frac{\partial \bar{\theta}}{\partial \phi}-\bar{w}^{*} \frac{\partial \bar{\theta}}{\partial z}+\bar{Q}-\frac{1}{\rho_{0}} \frac{\partial}{\partial z}\left(\rho_{0} \overline{v^{\prime} \theta^{\prime}} \frac{\bar{\theta}_{\varphi}}{a \bar{\theta}_{z}}\right) \\
& -\frac{1}{\rho_{0}} \frac{\partial}{\partial z}\left(\rho_{0} \overline{w^{\prime} \theta^{\prime}}\right) \\
\bar{v}^{*} \equiv & \bar{v}-\frac{1}{\rho_{0}} \frac{\partial}{\partial z}\left(\rho_{0} \frac{\overline{v^{\prime} \theta^{\prime}}}{\bar{\theta}_{z}}\right), \bar{w}^{*} \equiv \bar{w}+\frac{1}{a \cos \phi} \frac{\partial}{\partial \phi}\left(\cos \phi \frac{\overline{v^{\prime} \theta^{\prime}}}{\bar{\theta}_{z}}\right),
\end{aligned}
$$

where the overbar denotes the zonal mean, the prime is the departure from the zonal mean, subscripts denote partial differentiation, $a$ is the radius of Earth, $\theta$ is potential temperature, $\phi$ is latitude, $\rho_{0}$ is the reference density, $Q$ is diabatic heating, $\bar{v}^{*}$ is the residual mean meridional wind, and $\bar{w}^{*}$ is the residual mean vertical wind. The diabatic heating term is calculated from the residual in equation (4). The second term on the right-hand side is vertical advection, and the last (fifth) term is convergence of the vertical eddy heat flux. Vertical profiles of the thermodynamic balance and their difference from those in CTR around the TT are investigated below.

[37] Figure 5 shows annual mean vertical profiles of terms in the TEM thermodynamic budget and zonal mean temperature averaged between $10^{\circ} \mathrm{S}$ and $10^{\circ} \mathrm{N}$. The major terms in equation (4) are shown in Figure 5; those terms not shown are negligible. Figure 5a shows a cold point at $90 \mathrm{hPa}$ in CTR. Thermodynamic balance is largely maintained by vertical advection and diabatic heating at each level. Divergence of the vertical eddy heat flux slightly cools the TT.

[38] Figure 5b shows that the temperature decreases between 90 and $50 \mathrm{hPa}$ and increases between 150 and $110 \mathrm{hPa}$ in $2 \mathrm{SST}^{\prime}$. In addition, the temperature between 150 and $80 \mathrm{hPa}$ changes with convergence of the vertical eddy heat flux. Divergence of the vertical eddy heat flux is pronounced at $90 \mathrm{hPa}$; temperature decreases by $0.3 \mathrm{~K}$ at this height. Vertical advection leads to a reduced temperature above $80 \mathrm{hPa}$.

[39] Figure 5c shows that temperature increases between 100 and $50 \mathrm{hPa}$ and decreases between 150 and $130 \mathrm{hPa}$ in $0.5 \mathrm{SST}^{\prime}$. Convergence of the vertical eddy heat flux leads to a change in temperature between 150 and $80 \mathrm{hPa}$, and the 


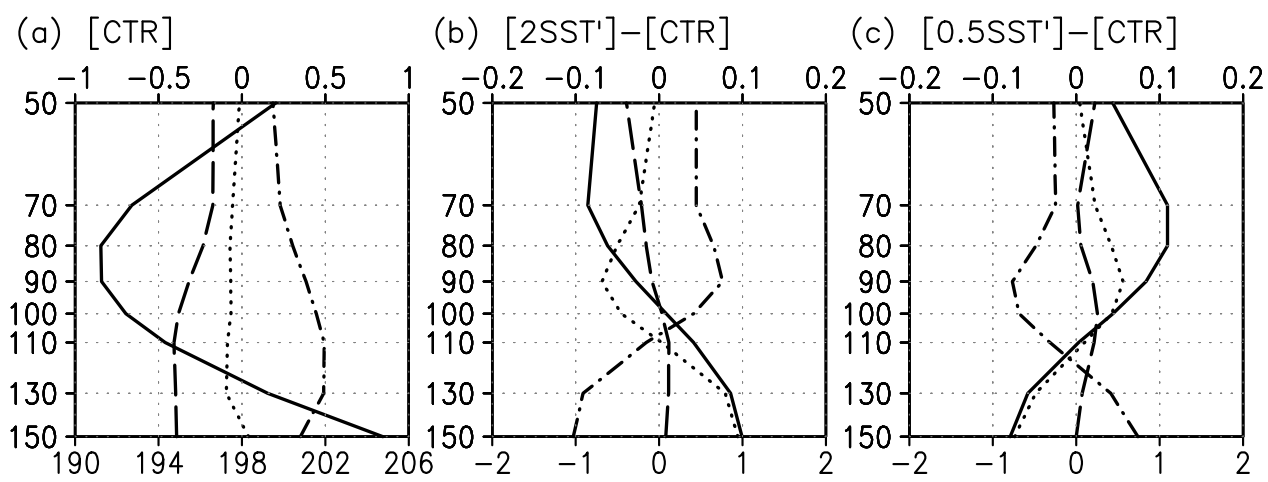

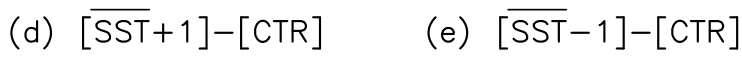

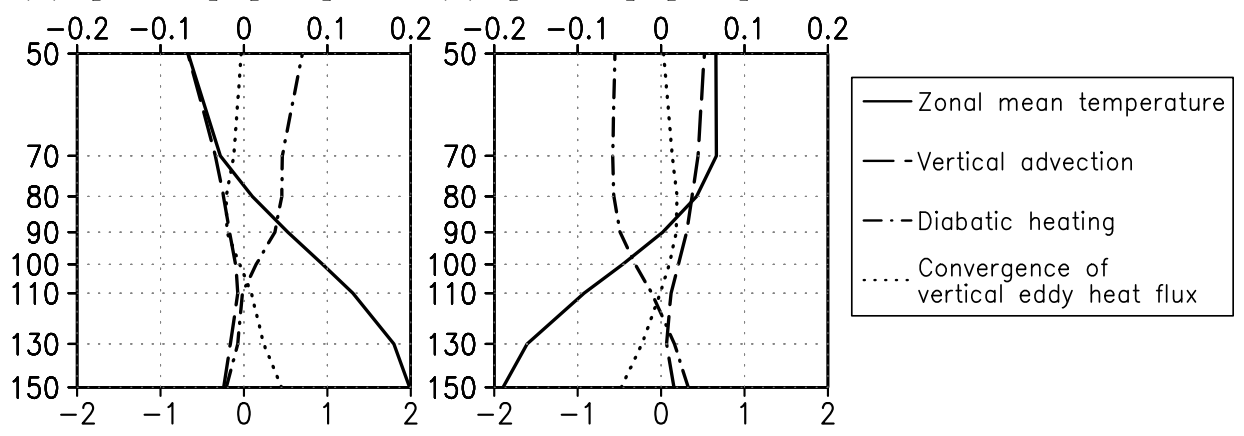

Figure 5. Comparison of annual mean vertical profiles of zonal mean temperature (bottom axis, K) and terms in the TEM thermodynamic equation (top axis, $\left.\mathrm{K} \mathrm{d}^{-1}\right)$ averaged over the tropics $\left(10^{\circ} \mathrm{S}-10^{\circ} \mathrm{N}\right)$ in (a) CTR and in the difference from CTR of (b) $2 \mathrm{SST}^{\prime}$, (c) $0.5 \mathrm{SST}^{\prime}$, (d) $\overline{\mathrm{SST}}+1$, and (e) $\overline{\mathrm{SST}}-1$.

temperature at $90 \mathrm{hPa}$ increases by $0.8 \mathrm{~K}$ because of convergence of the vertical eddy heat flux. The vertical advection leads to an increase in temperature above $80 \mathrm{hPa}$.

[40] Figure 5d shows that the temperature increases between 150 and $90 \mathrm{hPa}$ (peak warming is located at $300 \mathrm{hPa}$ because of diabatic heating) and decreases between 70 and $50 \mathrm{hPa}$ (because of vertical advection) in $\overline{\mathrm{SST}}+1$. The TT temperature increases because of diabatic heating.

[41] Figure 5e shows that the temperature decreases between 150 and $100 \mathrm{hPa}$ (peak cooling is located at $300 \mathrm{hPa}$ because of diabatic cooling), and vertical advection leads to an increase in temperature between 80 and $50 \mathrm{hPa}$ in $\overline{\text { SST }}-1$. The TT temperature is largely unchanged because the three terms cancel each other out.

[42] In EXP1, convergence of the vertical eddy heat flux results in marked changes in the temperature around the TT, whereas in EXP2, convergence of the vertical eddy heat flux is ineffective.

[43] Figure 6 shows the annual cycle of the thermodynamic budget at $90 \mathrm{hPa}$ in each experiment. Figure 6a shows that the TT temperature is warm from June to November (maximum in August at $193 \mathrm{~K}$ ) and cold from December to May (minimum in February at $189 \mathrm{~K}$ ). The annual cycle of TT temperature is in good agreement with the annual cycle of vertical advection, consistent with the results reported by Kerr-Munslow and Norton [2006]. Although convergence of the vertical eddy heat flux shows a similar annual cycle, it is of small magnitude.

[44] The TT temperature in $2 \mathrm{SST}^{\prime}$ shows slight increases in February and March and decreases in other months (Figure 6b), especially from September to November (minimum in October at $-0.7 \mathrm{~K}$ ). The annual cycle of convergence of the vertical eddy heat flux anomaly closely resembles that of the TT temperature anomaly, and the annual cycle of the vertical advection anomaly is similar to that of the TT temperature anomaly. The diabatic heating anomaly shows opposite variations to the TT temperature anomaly.

[45] The TT temperature in $0.5 \mathrm{SST}^{\prime}$ increases in all months, with the largest increase in December $(+1.3 \mathrm{~K}$, Figure 6c). The TT temperature anomaly is in good agreement with the anomalies of convergence of the vertical eddy heat flux and vertical advection. The diabatic heating anomaly shows opposite variations to the TT temperature anomaly.

[46] In $\overline{\mathrm{SST}}+1$, the TT temperature shows a large increase during March-May (maximum in April at $1.0 \mathrm{~K}$ ) (Figure 6d) and a minor increase during August-October (minimum in August at $0.1 \mathrm{~K}$ ). Vertical advection and convergence of the vertical eddy heat flux show a similar annual cycle anomaly to that of zonal mean temperature, especially during JulySeptember. Although the diabatic heating anomaly shows the opposite variations to the TT temperature anomaly, these anomalies have positive values.

[47] In $\overline{\mathrm{SST}}-1$ (Figure 6e), the TT temperature decreases from January to June (minimum in May at $-0.3 \mathrm{~K}$ ) and increases from July to December (maximum in August at $0.5 \mathrm{~K})$. Differences in the vertical advection and convergence of the vertical eddy heat flux are of small amplitude, but these annual cycles are similar to that of zonal mean temperature. The diabatic heating anomaly is of small 


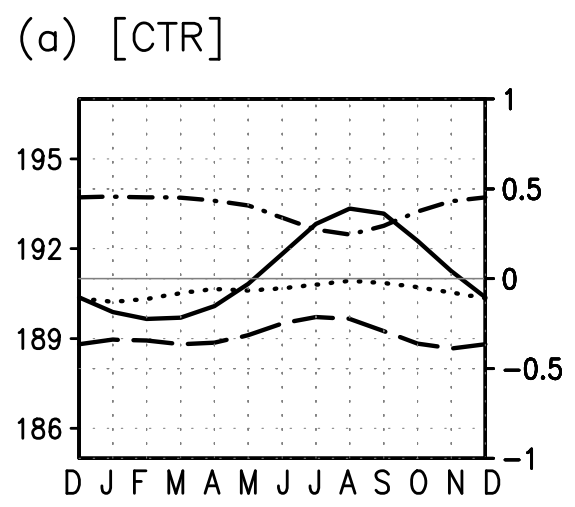

(b) $[2 \mathrm{SST} \cdot]-[\mathrm{CTR}]$

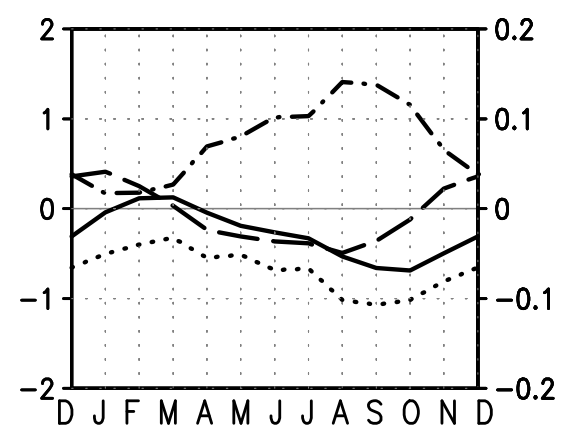

(e) $[\overline{\mathrm{SST}}-1]-[\mathrm{CTR}]$

(d) $[\overline{\mathrm{SST}}+1]-[\mathrm{CTR}]$

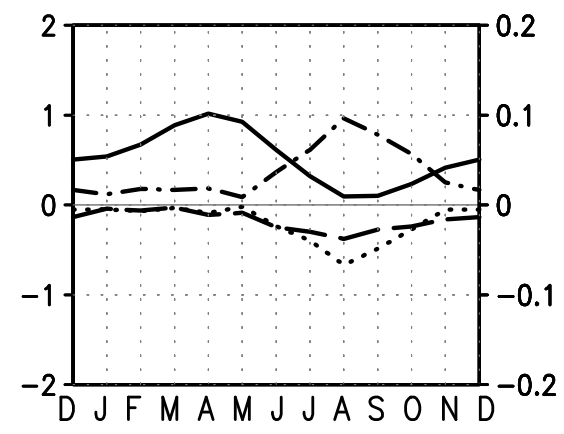

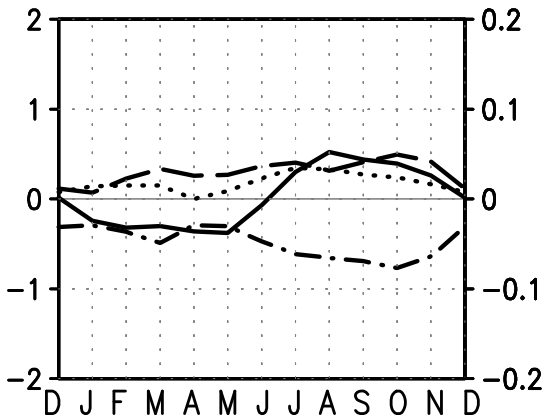

(c) $\left[0.5 S S T^{\prime}\right]-[\mathrm{CTR}]$

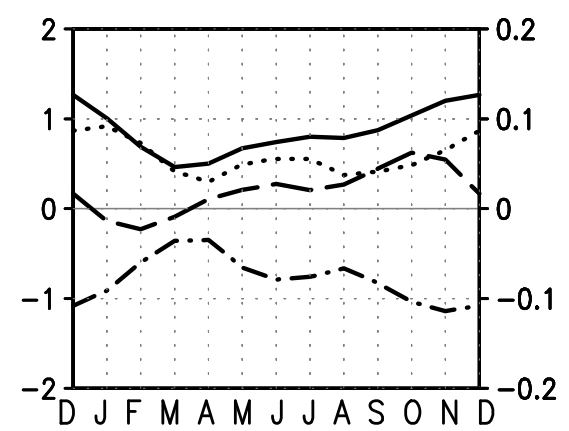

Figure 6. Annual cycles of zonal mean temperature (left axis, K) and terms in the TEM thermodynamic equation (right axis, $\mathrm{K} \mathrm{d}^{-1}$ ) (same plotted terms as in Figure 5) in (a) CTR and in the difference from CTR of (b) $2 \mathrm{SST}^{\prime}$, (c) $0.5 \mathrm{SST}^{\prime}$, (d) $\overline{\mathrm{SST}}+1$, and (e) $\overline{\mathrm{SST}}-1$ averaged over the tropics $\left(10^{\circ} \mathrm{S}-10^{\circ} \mathrm{N}\right)$ at $90 \mathrm{hPa}$.

amplitude compared with the TT temperature anomaly in the other cases and has negative values.

[48] In EXP1, the annual cycle of the TT temperature anomaly is similar to that of convergence of the vertical eddy heat flux anomaly. The strong cooling months in $2 \mathrm{SST}^{\prime}$ (August-October) and strong heating months in $0.5 \mathrm{SST}^{\prime}$ (December-February) due to convergence of the vertical eddy heat flux correspond to weak cooling months and strong cooling months in CTR, respectively.

[49] In EXP2, the diabatic heating anomaly has the same sign or weak counteraction as the TT temperature anomaly, which can be explained by the changing intensity of longwave radiation emitted from the sea surface due to variations in tropical SST. The annual cycle of TT temperature anomalies is poorly matched to the cycles of vertical advection and convergence of the vertical eddy heat flux. Previous studies have suggested that changes in tropical SST and cloud top height influence the long-wave radiative emission absorbed by the TT [e.g., Hartmann et al., 2001]. The role of diabatic heating in this regard will be considered in a future study.

\section{Vertical Eddy Heat Flux}

[50] Section 6 demonstrated that when a change occurs in the longitudinal gradient of tropical SST, convergence of the vertical eddy heat flux $\left(w^{\prime} \theta^{\prime}\right)$ (the last term in equation (4)) is important in terms of changes in the temperature of the TT layer. However, the importance of this term has not been emphasized in previous studies, such as studies of seasonal variations in TT temperature [e.g., Kerr-Munslow and Norton, 2006], because the amplitude of this term is so small that it is neglected in climatological mean cases (Figures 5a and 6a). To understand in detail the causes of the vertical eddy heat flux, we investigate the time scale and spatial structure of perturbations of the vertical velocity and potential temperature that drive the vertical eddy heat flux around the TT. The months considered in this analysis were those with the largest amplitude of convergence of vertical eddy heat flux (i.e., December-February in both CTR and 0.5SST').

[51] Perturbation of the vertical velocity can be decomposed into the monthly mean perturbation and the deviation from the monthly mean perturbation, as follows:

$$
w^{\prime}=\left[w^{\prime}\right]+w^{\prime *},
$$

where the brackets indicate the monthly mean and the asterisk indicates the deviation of the monthly mean. The monthly mean of the vertical eddy heat flux can then be decomposed into a stationary part, which consists of monthly mean perturbations, and a transient part, which consists of the deviations of the monthly mean perturbation, as follows:

$$
\left[w^{\prime} \theta^{\prime}\right]=\left[w^{\prime}\right]\left[\theta^{\prime}\right]+\left[w^{\prime *} \theta^{\prime *}\right],
$$

where the first term on the right-hand side is the stationary part of the vertical eddy heat flux and the second term is the transient part. 

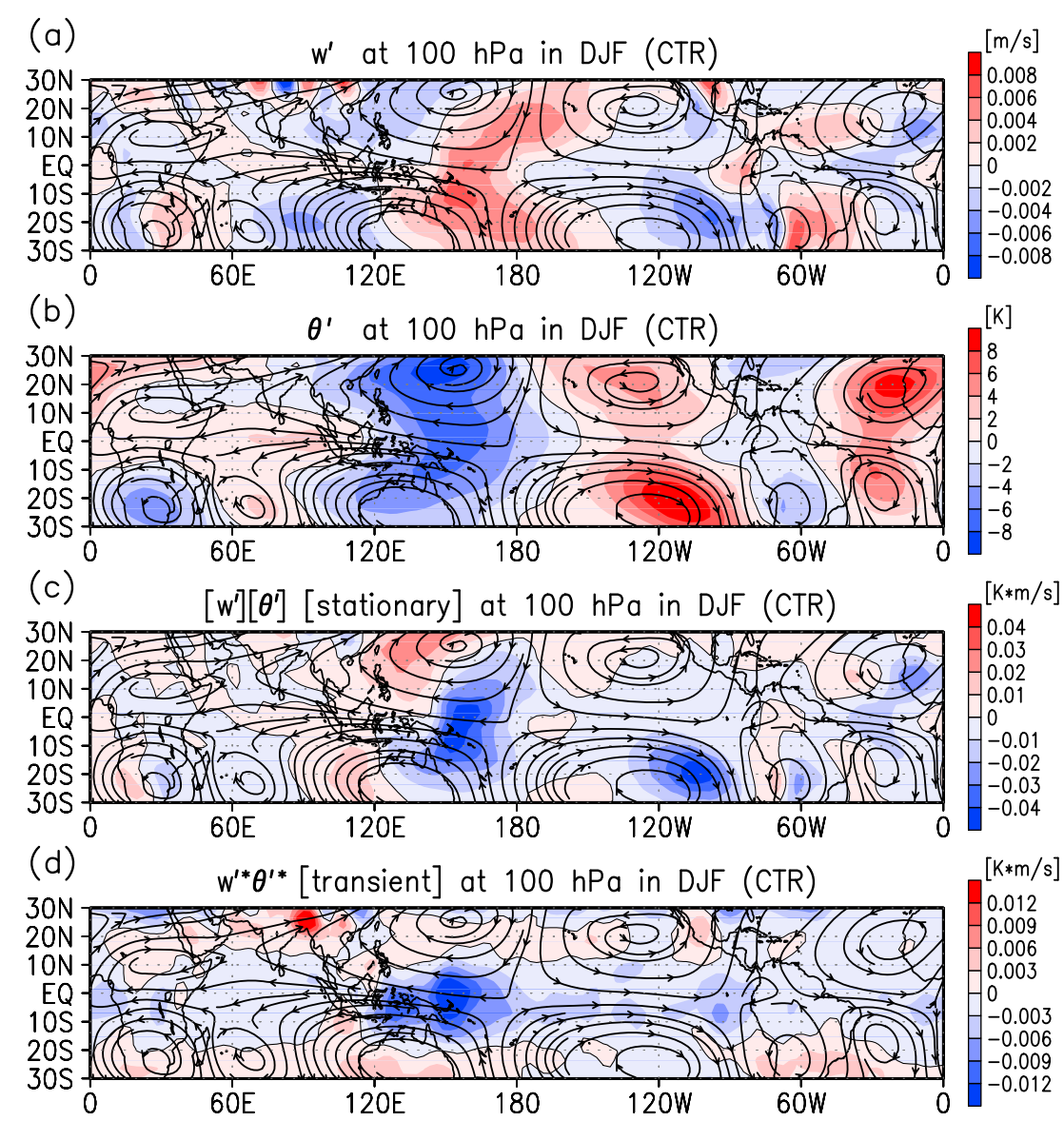

Figure 7. Horizontal fields of departures from the zonal mean of stream functions (black arrowed contours shown qualitatively): (a) vertical velocity $\mathrm{w}^{\prime}$, (b) potential temperature $\theta^{\prime}$, (c) stationary part of the vertical eddy heat flux $\left[\mathrm{w}^{\prime}\right]\left[\theta^{\prime}\right]$, and (d) transient part of the vertical eddy heat flux $\mathrm{w}^{\prime *} \theta^{\prime *}$ in CTR for the period December-February at $100 \mathrm{hPa}$.

[52] Figure 7 shows horizontal wind, perturbations in both vertical velocity $w^{\prime}$ and potential temperature $\theta^{\prime}$, and the vertical eddy heat flux decomposed into the stationary part $\left[w^{\prime}\right]\left[\theta^{\prime}\right]$ and transient part $\left[w^{\prime *} \theta^{\prime *}\right]$ for the period between December and February in CTR. A pair of strong anticyclones around the western Pacific straddles the equator, with large positive $w^{\prime}$ and large negative $\theta^{\prime}$ located between the anticyclones. Therefore, the stationary part of the vertical eddy heat flux is strongly negative in the equatorial western Pacific, as well as being negative in the area south of the equatorial eastern Pacific and in the equatorial Atlantic. Although the transient part of the vertical eddy heat flux also has large negative values along the equator, its amplitude is smaller than that of the stationary part (note that the range of values in the scale for the stationary vertical eddy heat flux is about 3 times greater than that in the scale for the transient flux). This circulation pattern, with anticyclones and westerly winds in the equatorial Pacific, is the MatsunoGill pattern, which is induced by localized heating in the equatorial western Pacific [Matsuno, 1966; Gill, 1980]. However, the vertical eddy heat flux in the equatorial western Pacific has a relatively small negative value at $70 \mathrm{hPa}$ $\left(0 \approx\left(w^{\prime} \theta^{\prime}\right)_{70 \mathrm{hPa}}>\left(w^{\prime} \theta^{\prime}\right)_{100 \mathrm{hPa}} ;\right.$ not shown $)$. Therefore, difference of the vertical eddy heat flux between 70 and $100 \mathrm{hPa}$ generates divergence of the vertical eddy heat flux $\left(-\rho_{0}^{-1} \partial\left(\rho_{0} w^{\prime} \theta^{\prime}\right) / \partial z<0\right)$ in the TT, and divergence of the vertical eddy heat flux cools the TT.

[53] Figure 8 shows differences in the vertical eddy heat flux between $0.5 \mathrm{SST}^{\prime}$ and CTR at $100 \mathrm{hPa}$ during the period December-February. The amplitudes of vertical velocity and potential temperature are reduced in the tropics, especially in the equatorial western Pacific and south of the equatorial eastern Pacific. The circulation pattern is obviously weakened in the tropics, except between $0^{\circ}$ and $60^{\circ} \mathrm{E}$. The vertical eddy heat flux in the stationary part is offset in the tropics, especially in the equatorial western Pacific and south of the equatorial eastern Pacific, and the amplitude of the vertical eddy heat flux in the transient part is offset along the equator. Therefore, divergence of the vertical eddy heat flux is reduced in the TT, and the TT temperature increases because of a reduction in divergence of the vertical eddy heat flux. The Matsuno-Gill pattern is visibly weakened at $100 \mathrm{hPa}$ in $0.5 \mathrm{SST}^{\prime}$, coincident with a reduction in divergence of the vertical eddy heat flux.

[54] Figure 9 shows vertical profiles of the annual mean zonal mean vertical eddy heat flux averaged over the tropics in CTR and EXP1. The vertical eddy heat flux is divided into two time scales: longer and shorter than 1 month. The stationary part of the vertical eddy heat flux shows a marked change at around $100 \mathrm{hPa}$ in EXP1. Although the transient 

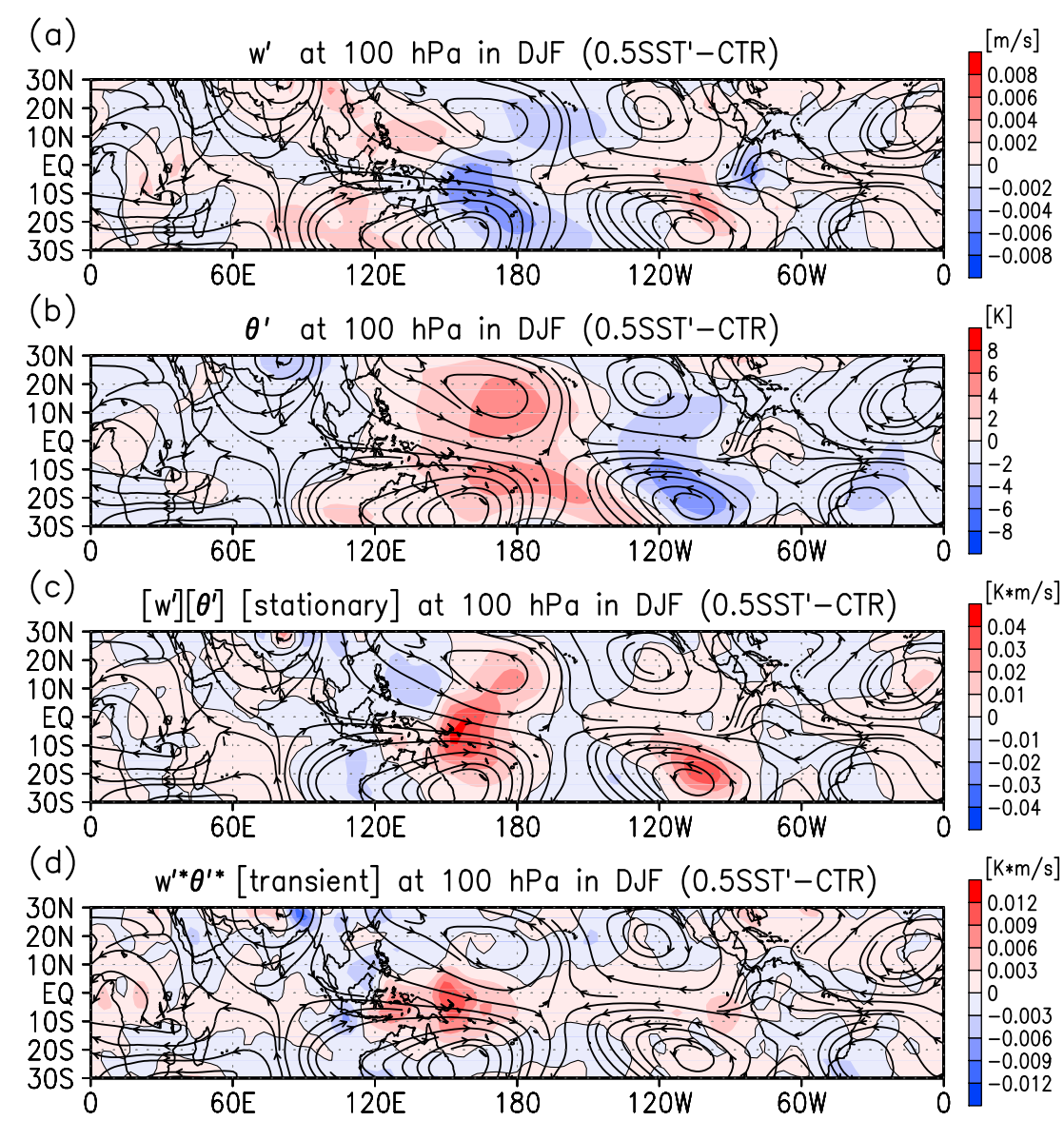

Figure 8. As in Figure 7 but for differences in $0.5 \mathrm{SST}^{\prime}$ from CTR.

part of the vertical eddy heat flux has similar amplitude to that of the stationary part, its vertical gradient is small around the TT.

[55] Localized convection generates the Matsuno-Gill pattern in the tropical troposphere. Consequently, ascending flow in the equatorial western Pacific transports the cold perturbation at $100 \mathrm{hPa}$ upward (i.e., negative vertical eddy heat flux, Figure 10). Because the amplitude of the negative vertical eddy heat flux is reduced upward in the equatorial western Pacific, the vertical eddy heat flux diverges in the $\mathrm{TT}$, leading to a reduction in TT temperature. A reduction in the longitudinal gradient of tropical SST results in weakening of the Matsuno-Gill pattern. Consequently, the TT temperature increases in response to a decrease in the divergence of the vertical eddy heat flux in $0.5 \mathrm{SST}^{\prime}$. The longitudinal gradient of tropical SST is reduced during El Niño events.

\section{Realistic SST Experiment}

[56] Figure 11 shows comparisons of time series of temperature and the TEM thermodynamic terms in the TT from January 1996 to December 1999. The TT temperature
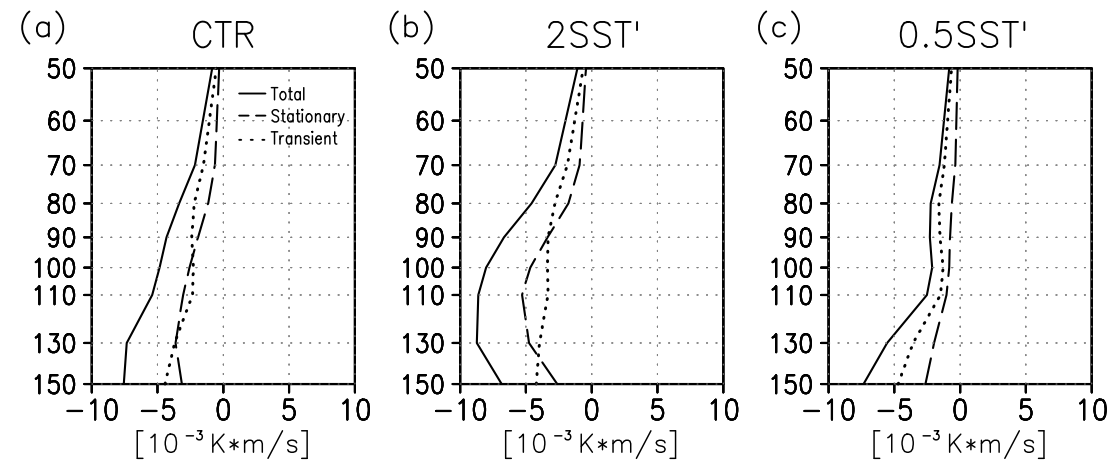

Figure 9. Vertical profiles of annual mean zonal mean vertical eddy heat flux averaged over the tropics $\left(10^{\circ} \mathrm{S}-10^{\circ} \mathrm{N}\right)$ between 50 and $150 \mathrm{hPa}$ in (a) CTR, (b) $2 \mathrm{SST}^{\prime}$, and (c) $0.5 \mathrm{SST}^{\prime}$. Solid lines indicate the total value of the vertical eddy heat flux, dashed lines are the stationary part of the vertical eddy heat flux, and dotted lines are the transient part of the vertical eddy heat flux. 


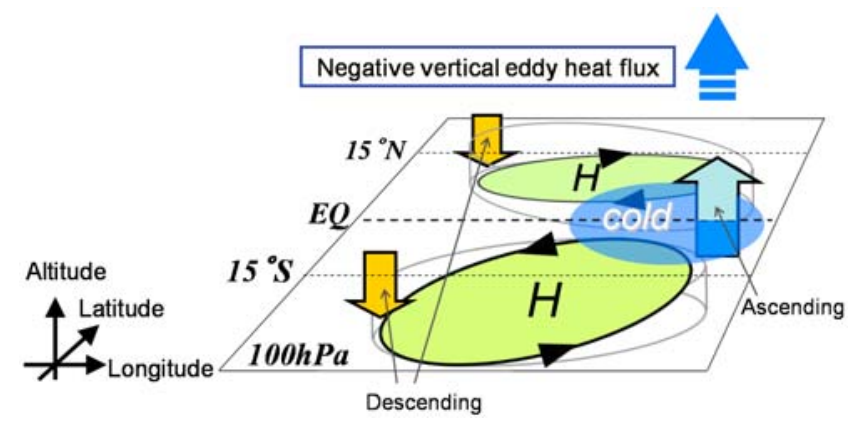

Figure 10. Schematic showing typical wave activity in the tropical western Pacific at $100 \mathrm{hPa}$. $\mathrm{H}$ indicates a highpressure anomaly, the blue oval is a cold anomaly, the upward arrow is an ascending anomaly, and downward arrows indicate a descending anomaly. These cold and ascending anomalies generate negative vertical eddy heat flux. in the experiment using observed SST (EXP3) has a cold bias of about $2.5 \mathrm{~K}$. The variations in TT temperature in EXP3 are consistent with those of ERA-Interim and ERA-40 except for high temperatures during the boreal summer of 1999 and low temperatures during the boreal summer of 1996. In January 1998, when El Niño reached its peak, the TT temperature is higher than in January of other years (1996, 1997, and 1999). This feature is seen in between 100 and $80 \mathrm{hPa}$ of all the data sets, including EXP3. At the same time, divergence of the vertical eddy heat flux is reduced in amplitude, which acts to increase TT temperature. Also in January of 1998, for ERA-Interim and ERA-40, divergence of the vertical eddy heat flux leads to an increase in TT temperature. Despite these similarities among the three data sets, there exist large differences in vertical advection until 1998. The large amplitudes of vertical advection and diabatic heating in ERA-40 are seen until August 1998 because in ERA-40, upward flow around the TT and B-D circulation is overestimated; for example, on the basis of the chemical transport model, Schoeberl et al. [2003] and
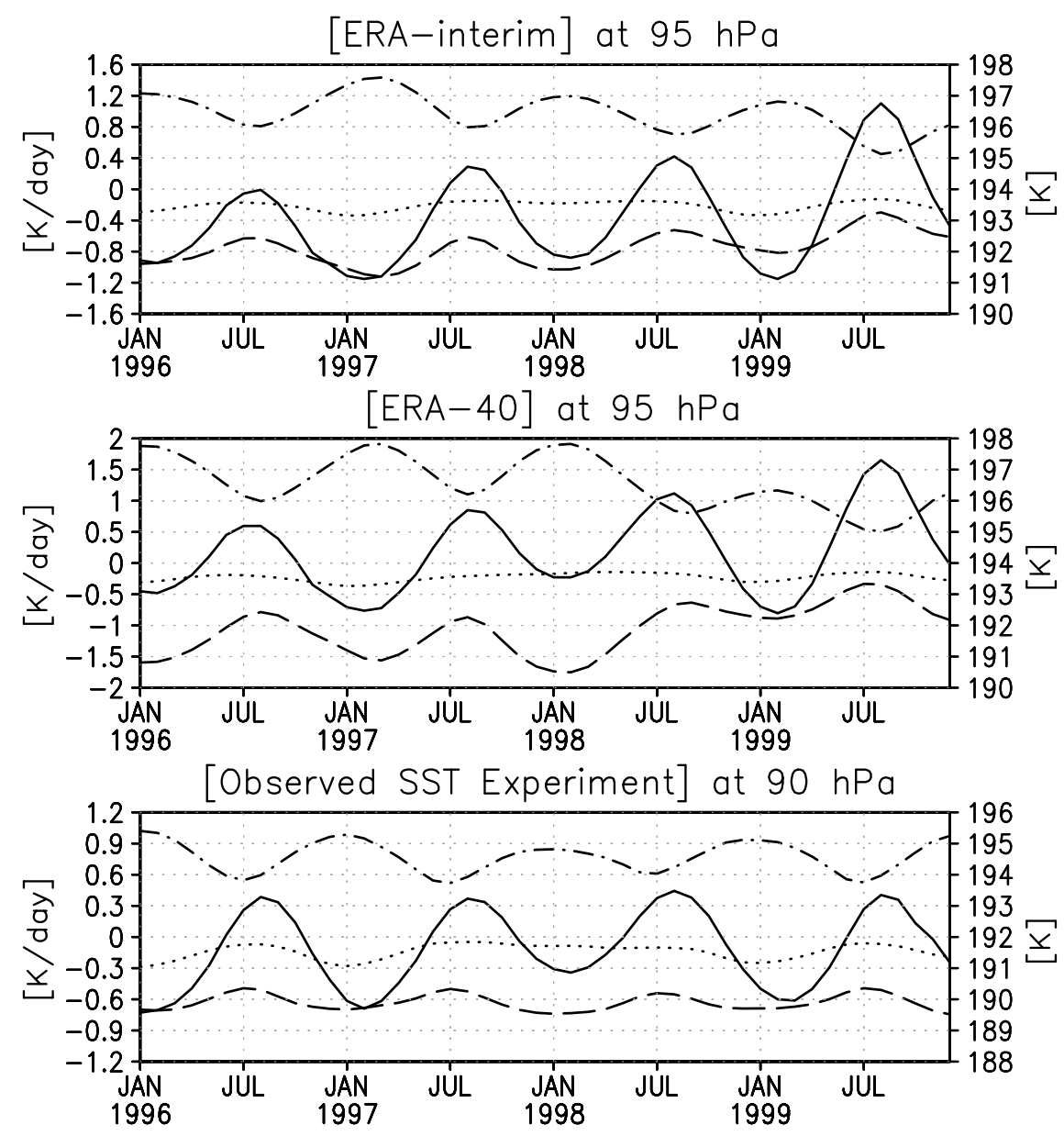

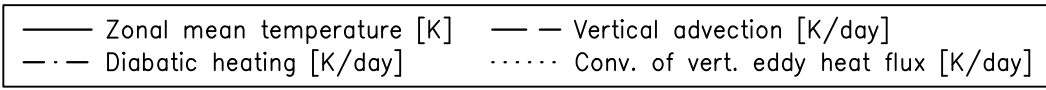

Figure 11. Comparison of the time series of zonal mean temperature $(\mathrm{K})$ and terms in the TEM thermodynamic equation $\left(\mathrm{K} \mathrm{d}^{-1}\right)$ (same plotted terms as in Figures 5 and 6) averaged over the tropics $\left(10^{\circ} \mathrm{S}-10^{\circ} \mathrm{N}\right)$. (top) ERA-Interim at $95 \mathrm{hPa}$. (middle) ERA-40 at $95 \mathrm{hPa}$. (bottom) Observed SST experiment at $90 \mathrm{hPa}$. 

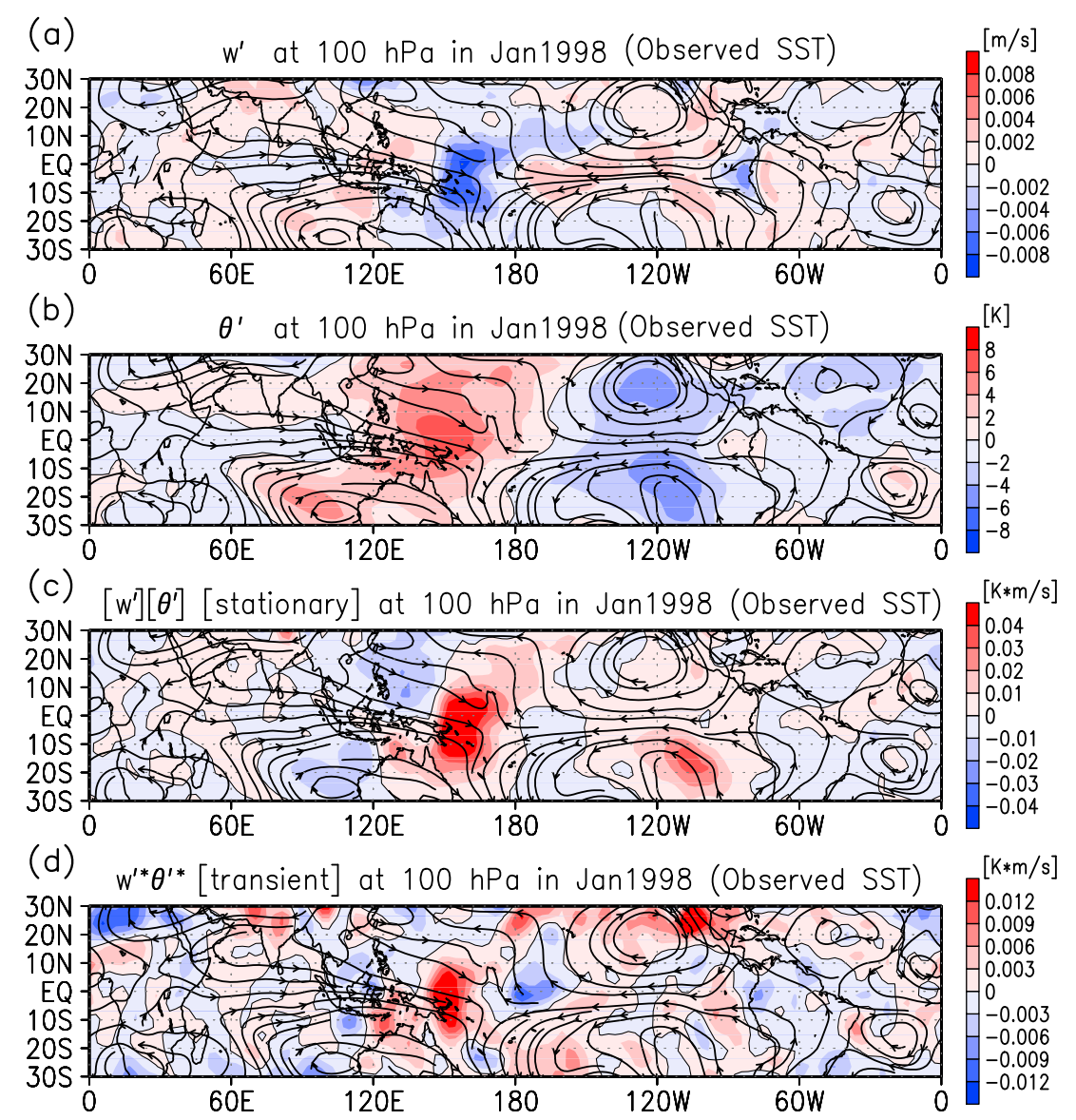

Figure 12. Horizontal field differences in departures from the zonal mean of stream functions (black arrowed contours shown qualitatively): (a) vertical velocity $\mathrm{w}^{\prime}$, (b) potential temperature $\theta^{\prime}$, (c) stationary part of the vertical eddy heat flux $\left[\mathrm{w}^{\prime}\right]\left[\theta^{\prime}\right]$, and (d) transient part of the vertical eddy heat flux $\mathrm{w}^{\prime} * \theta^{\prime} *$ in the observed SST experiment from climatological means (CTR in January) for January 1998 at $100 \mathrm{hPa}$.

Monge-Sanz et al. [2007] suggested that the strength of the B-D circulation is overestimated in ERA-40. These amplitudes showed a marked reduction following the August 1998 launch of NOAA 15, which is equipped with the highvertical-resolution Advanced Microwave Sounding Unit-A (AMSU-A).

[57] Figure 12 shows differences in the vertical eddy heat flux, vertical velocity, and potential temperature between EXP3 and CTR for January 1998. The characteristics of the results obtained from EXP3 are similar to those obtained from $0.5 \mathrm{SST}^{\prime}$ (Figure 8). In particular, in both the equatorial western Pacific and the area south of the equatorial eastern Pacific, the stationary part of the vertical eddy heat flux is similar to the result obtained from $0.5 \mathrm{SST}^{\prime}$.

[58] Figure 13 shows fields similar to those in Figure 12 but calculated from ERA-Interim. Compared with EXP3, the stationary part of the vertical eddy heat flux in ERAInterim has a broader and weaker positive region around the equatorial western Pacific. Consequently, the stationary vertical eddy heat flux between $10^{\circ} \mathrm{S}$ and $10^{\circ} \mathrm{N}$ in EXP3 has a thermodynamic effect on the TT similar to that in ERA-Interim.

[59] The positive anomalies in the stationary part of the vertical eddy heat flux in both EXP3 and ERA-Interim decay upward to $70 \mathrm{hPa}$, and the reduction in divergence of the vertical eddy heat flux leads to an increase in TT temperature. Consequently, the TT temperature in January 1998 is warmer than that in January of any other year. The EXP3 results for the 1997-1998 El Niño event are in good agreement with the results of ERA-Interim and ERA-40 in terms of vertical eddy heat flux and TT temperature. These findings indicate that TT temperature change due to vertical eddy heat flux is not just a feature of the numerical model: It occurs in the real world, associated with the changing longitudinal gradient of tropical SST.

\section{Concluding Remarks}

[60] The main aim of this investigation was to study the response of TT temperature to various patterns of tropical SSTs. Four different patterns of tropical SSTs were used in a numerical model as the boundary conditions. The response of the TT was discussed on the basis of the results of numerical experiments and an analysis of the ERA-Interim and ERA-40 data sets. On the basis of these analyses, we arrived at the following conclusions.

[61] 1. With increasing (decreasing) longitudinal gradient of tropical SST, TT temperature and tropical upper troposphere temperature decrease and increase (increase and decrease), respectively, because of strengthening (weakening) 

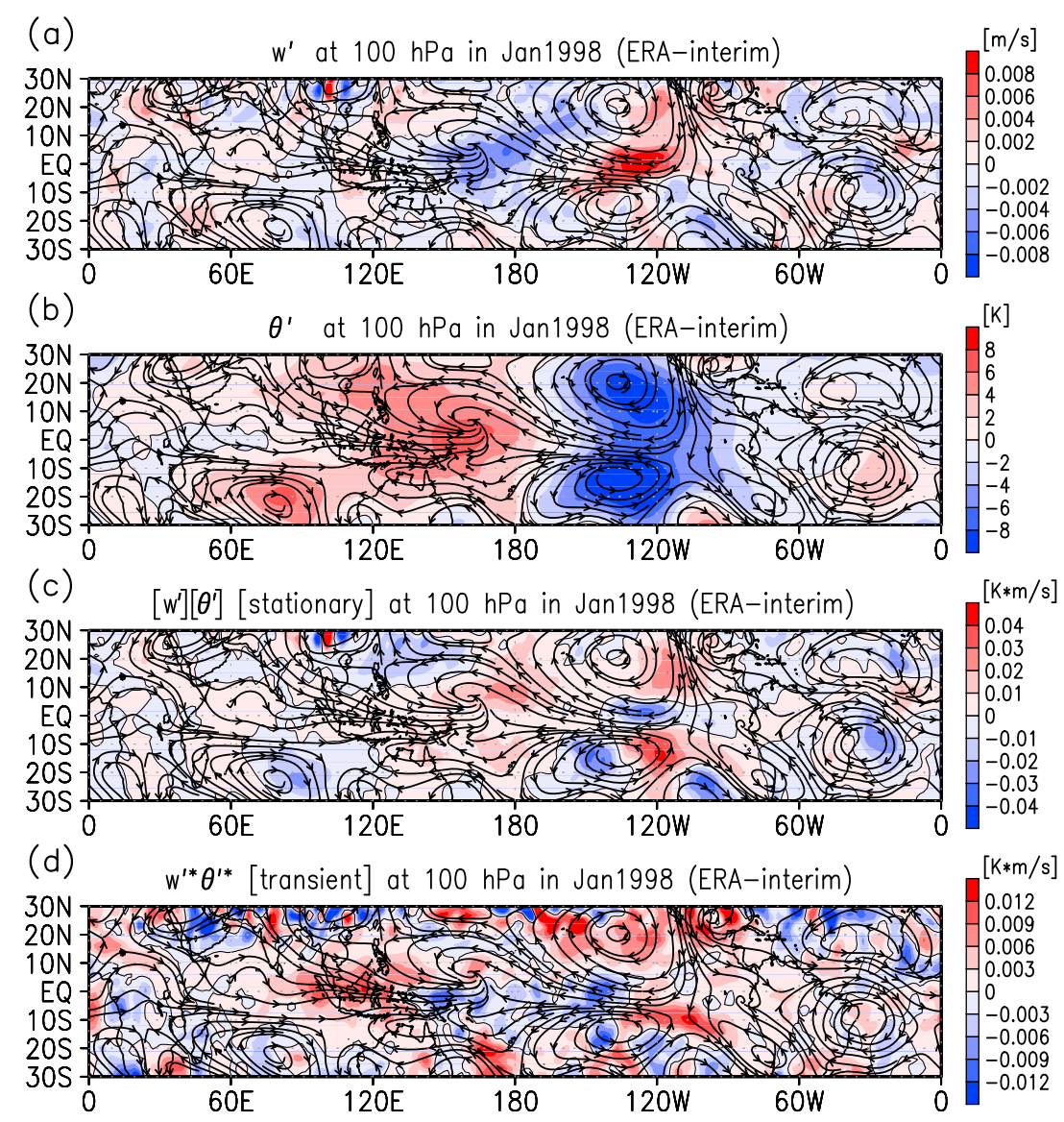

Figure 13. As in Figure 12 but calculated from ERA-Interim.

of the vertical eddy heat flux. Convergence of the vertical eddy heat flux shows a negative correlation with the strength of the Matsuno-Gill pattern.

[62] 2. Enhanced longitudinal gradient of tropical SST results in intensification of circulation (with ascent centered on the equator) and poleward meridional flow around the TT. This circulation weakens with a decrease in the gradient of SST.

[63] 3. With increasing mean tropical SST, the annual mean TT temperature increases because of diabatic heating; however, with decreasing mean tropical SST, the annual mean TT temperature is unchanged because of counteracting thermodynamic effects. In both cases, change in the annual cycle of TT temperature shows poor agreement with vertical advection and convergence of the vertical eddy heat flux.

[64] 4. Vertical eddy heat flux caused by a reduction of the longitudinal gradient of tropical SST due to El Niño (1997-1998) results in an increase in TT temperature in the results of ERA-Interim and ERA-40 and in the output of the numerical experiment using observed SST.

[65] 5. In terms of climatological seasonal variation, our experimental results are consistent with the findings of Kerr-Munslow and Norton [2006]. Variations in seasonal TT temperature are controlled mainly by the vertical advection induced by equatorial waves; however, interannual variations in TT temperature cannot be explained solely in terms of vertical advection.

[66] The fifth term in equation (4), which represents convergence of the vertical eddy heat flux, has been largely neglected in previous studies, such as those of seasonal variations in TT temperature; however, the results of the present study demonstrate that this term makes a major contribution to interannual variations in TT temperature.

[67] The localized deep convection around the tropical western Pacific enhances the ascending motion; thus, $w^{\prime}>0$. Interestingly, potential temperature perturbations around the tropical western Pacific at $100 \mathrm{hPa}$ are negative $\left(\theta^{\prime}<0\right)$; consequently, the vertical motion generates a negative eddy heat flux $\left(\overline{w^{\prime} \theta^{\prime}}<0\right)$ that acts to reduce the temperature in the TT because of the upward decay of this pattern. Figure 10 shows a schematic picture of this special pattern.

[68] With increasing longitudinal gradient of tropical SST, localized convection develops around the tropical western Pacific, exciting tropical waves and enhancing the Matsuno-Gill pattern. Consequently, divergence of the vertical eddy heat flux is intensified around the TT, leading in turn to a decrease in TT temperature. However, with a reduction in the longitudinal gradient of tropical SST, as occurs during an El Niño event, the localized deep convection weakens around the tropical western Pacific, meaning that divergence of the vertical eddy heat flux is reduced around the TT, leading in turn to an increase in TT temperature. These results are similar to those reported by Hatsushika and Yamazaki [2001], who found that between December and February in El Niño years the cold tropopause region becomes zonally elongated and meridionally narrow, and that the ascending area shifts eastward and weakens around the TT. 
[69] When the mean tropical SST increases or decreases, the TT temperature is controlled not only by vertical advection but also by diabatic heating. It is highly possible that long-wave radiative absorption shows an increase (decrease) around the TT because of increasing (decreasing) tropical SST. In addition, TT temperature increases (decreases) with lowering (rising) of the cloud top height [Hartmann et al., 2001]. Lowering (rising) of the cloud top height results in high (low) cloud top temperature and, consequently, an intensification (reduction) of outgoing long-wave radiation from the cloud top. Additional research is required to explain the effect of diabatic heating on TT temperature.

[70] This paper demonstrated the importance of the vertical eddy heat flux on interannual variations in TT temperature. The vertical eddy heat flux is likely to play a role in global warming and century-scale variations around the TT, as many climate models predict an El Niño-like climate in the future and the weakening of Walker circulation [Vecchi et al., 2006; Yamaguchi and Noda, 2006].

\section{Notation}

$a$ radius of Earth, $\mathrm{m}$.

$Q$ diabatic heating, $\mathrm{K} \mathrm{s}^{-1}$.

$t$ time, s.

$v$ meridional component of velocity (northward), $\mathrm{m} \mathrm{s}^{-1}$.

$\bar{v}^{*}$ residual mean meridional velocity, $\mathrm{m} \mathrm{s}^{-1}$.

$w$ vertical component of velocity, $\mathrm{m} \mathrm{s}^{-1}$.

$\bar{w}^{*}$ residual mean vertical velocity, $\mathrm{m} \mathrm{s}^{-1}$.

$z \quad$ vertical coordinate in $\log$ pressure system, $\mathrm{m}$.

$\theta$ potential temperature, $\mathrm{K}$.

$\rho_{0}$ reference density, $\mathrm{kg} \mathrm{m}^{-3}$.

$\phi$ latitude.

[71] Acknowledgments. This study was supported in part by the Ministry of the Environment, Japan, via the Global Environment Research Fund (A-071). We would like to thank K. Hamilton and M. Kadota for helpful discussion. We would also like to thank the Center for Climate System Research (CCSR), University of Tokyo, and the National Institute of Environmental Studies (NIES), Japan, for use of the CCSR/NIES AGCM. Analyses and figures were created using the Grid Analysis and Display System (GrADS).

\section{References}

Andrews, D. G., J. R. Holton, and C. B. Leovy (1987), Middle Atmosphere Dynamics, 489 pp., Elsevier, New York.

Fueglistaler, S., M. Bonazzola, P. H. Haynes, and T. Peter (2005), Stratospheric water vapor predicted from the Lagrangian temperature history of air entering the stratosphere in the tropics, J. Geophys. Res., 110, D08107, doi:10.1029/2004JD005516.

Fueglistaler, S., B. Legras, A. Beljaars, J.-J. Morcrette, A. Simmons, A. M. Tompkins, and S. Uppala (2009), The diabatic heat budget of the upper troposphere and lower/mid stratosphere in ECMWF reanalyses, $Q$. J.R. Meteorol. Soc., 135, 21-37, doi:10.1002/qj.361.

Gates, W. L. (1992), AMIP: The Atmospheric Intercomparison Project, Bull. Am. Meteorol. Soc., 73, 1962-1970, doi:10.1175/1520-0477 (1992)073<1962:ATAMIP>2.0.CO;2.

Gill, A. E. (1980), Some simple solutions for heat-induced tropical circulation, Q. J. R. Meteorol. Soc., 106, 447-462, doi:10.1002/ qj.49710644905.

Hartmann, D. L. (2007), The atmospheric general circulation and its variability, J. Meteorol. Soc. Jpn., 85B, 123-143, doi:10.2151/jmsj.85B.123.

Hartmann, D. L., J. R. Holton, and Q. Fu (2001), The heat balance of the tropical tropopause, cirrus, and stratospheric dehydration, Geophys. Res. Lett., 28, 1969-1972, doi:10.1029/2000GL012833.
Hatsushika, H., and K. Yamazaki (2001), Interannual variations of temperature and vertical motion at the tropical tropopause associated with ENSO, Geophys. Res. Lett., 28, 2891-2894, doi:10.1029/2001GL012977.

Hatsushika, H., and K. Yamazaki (2003), Stratospheric drain over Indonesia and dehydration within the tropical tropopause layer diagnosed by air parcel trajectories, J. Geophys. Res., 108(D19), 4610, doi:10.1029/ 2002JD002986.

Haynes, P. H., C. J. Marks, M. E. McIntyre, T. G. Shepherd, and K. P. Shine (1991), On the "downward control" of extratropical diabatic circulations by eddy-induced mean zonal forces, J. Atmos. Sci., 48, 651-678, doi:10.1175/1520-0469(1991)048<0651:OTCOED>2.0.CO;2.

Highwood, E. J., and B. J. Hoskins (1998), The tropical tropopause, Q. J. R. Meteorol. Soc., 124, 1579-1604, doi:10.1002/qj.49712454911.

Holton, J. R., and A. Gettleman (2001), Horizontal transport and the dehydration of the stratosphere, Geophys. Res. Lett., 28, 2799-2802, doi:10.1029/2001GL013148.

Holton, J. R., P. H. Haynes, M. E. McIntyre, A. R. Douglass, R. B. Rood, and L. Pfister (1995), Stratosphere-troposphere exchange, Rev. Geophys., 33, 403-439, doi:10.1029/95RG02097.

Kerr-Munslow, A. M., and W. A. Norton (2006), Tropical wave driving of the annual cycle in tropical tropopause temperatures. Part I: ECMWF analyses, J. Atmos. Sci., 63, 1410-1419, doi:10.1175/JAS3697.1.

Matsuno, T. (1966), Quasi-geostrophic motions in the equatorial area, J. Meteorol. Soc. Jpn., 44, 25-43.

Monge-Sanz, B. M., M. P. Chipperfield, A. J. Simmons, and S. M. Uppala (2007), Mean age of air and transport in a CTM: Comparison of different ECMWF analyses, Geophys. Res. Lett., 34, L04801, doi:10.1029/ 2006GL028515.

Norton, W. A. (2006), Tropical wave driving of the annual cycle in tropical tropopause temperatures. Part II: Model results, J. Atmos. Sci., 63, 1420-1431, doi:10.1175/JAS3698.1.

Numaguti, A., M. Takahashi, T. Nakajima, and A. Sumi (1995), Development of an atmospheric general circulation model, in Climate System Dynamics and Modelling, edited by T. Matsuno, pp. 1-27, Cent. for Clim. Syst. Res., Tokyo.

Olsen, M. A., M. R. Schoeberl, and J. E. Nielsen (2007), Response of stratospheric circulation and stratosphere-troposphere exchange to changing sea surface temperatures, J. Geophys. Res., 112, D16104, doi:10.1029/ 2006JD008012.

Plumb, R. A., and J. Eluszkiewicz (1999), The Brewer-Dobson circulation: Dynamics of the tropical upwelling, J. Atmos. Sci., 56, 868-890, doi:10.1175/1520-0469(1999)056<0868:TBDCDO>2.0.CO;2.

Schoeberl, M. R., A. R. Douglass, Z. Zhu, and S. Pawson (2003), A comparison of the lower stratospheric age spectra derived from a general circulation model and two data assimilation systems, J. Geophys. Res., 108(D3), 4113, doi:10.1029/2002JD002652.

Simmons, A. J., and J. K. Gibson (2000), The ERA-40 project plan, ERA-40 Proj. Rep. Ser. 1, 63 pp., Eur. Cent. for Medium-Range Weather Forecasts, Reading, U. K.

Simmons, A. J., S. M. Uppala, D. Dee, and S. Kobayashi (2006), ERAInterim: New ECMWF reanalysis product from 1989 onwards, ECMWF Newsl., 110, 25-35.

Trenberth, K. E., and L. Smith (2006), The vertical structure of temperature in the tropics: Different flavors of El Niño, J. Clim., 19, 4956-4970, doi:10.1175/JCLI3891.1.

Uppala, S. M., et al. (2005), The ERA-40 re-analysis, Q. J. R. Meteorol. Soc., 131, 2961-3012, doi:10.1256/qj.04.176.

Uppala, S. M., D. Dee, S. Kobayashi, P. Berrisford, and A. Simmons (2008), Towards a climate data assimilation system: Status update of ERA-Interim, ECMWF Newsl., 115, 12-18.

Vecchi, G. A., B. J. Soden, A. T. Wittenberg, I. M. Held, and A. Leetmaa (2006), Weakening of tropical Pacific atmospheric circulation due to anthropogenic forcing, Nature, 441, 73-74, doi:10.1038/nature04744.

Yamaguchi, K., and A. Noda (2006), Global warming patterns over the North Pacific: ENSO versus AO, J. Meteorol. Soc. Jpn., 84, 221-241, doi:10.2151/jmsj.84.221.

Yulaeva, E., J. R. Holton, and J. M. Wallace (1994), On the cause of the annual cycle in tropical lower-stratospheric temperatures, J. Atmos. Sci., 51, 169-174, doi:10.1175/1520-0469(1994)051<0169:OTCOTA $>$ 2.0.CO;2.

K. Yamazaki, Faculty of Environmental Earth Science, Hokkaido University, Kita 10, Nishi 5 Kita-ku, Sapporo, Hokkaido 060-0810, Japan.

K. Yoshida, Graduate School of Environmental Science, Hokkaido University, Kita 10, Nishi 5 Kita-ku, Sapporo, Hokkaido 060-0810, Japan. (kohei@ees.hokudai.ac.jp) 